\title{
Selective cognitive patterns resulting from bilateral hippocampal ischemia
}

David Cachia, Joan Swearer, Warren Ferguson, Majaz Moonis

University of Massachusetts, Worcester, MA, USA

Submitted: 26 August 2010

Accepted: 25 October 2010

Arch Med Sci 2011; 7, 1: 168-172

DOI: 10.5114/aoms.2011.20626

Copyright $\odot 2011$ Termedia \& Banach

\section{Abstract}

A 54-year-old diabetic, hypertensive man with poorly controlled moderate-severe sleep apnea presented with acute onset of severe anterograde amnesia and well preserved remote memory without additional cognitive impairment. Investigations, including a lumbar puncture, electroencephalogram (EEG) and serology testing ruled out infectious, neoplastic and epilleptogenic causes. MRI taken 10 days after symptom onset, was suggestive of sequential ischemic damage to both hippocampal formations. Neuropyschological evaluation suggested a focal and dense amnestic syndrome with little improvement over time. The bilateral nature of hippocampal ischemia though has been reported, is rare.

Key words: amnesia, memory, MRI, stroke.

\section{Case report}

The patient is a 54-year-old gentleman, non-smoker, with a medical history of type 2 diabetes, hypertension, hypercholesterolemia, moderate-severe obstructive sleep apnea and depression. His diabetes was diagnosed in 1997 on routine testing, when he was started on glypizide $5 \mathrm{mg}$ bid later increased to $10 \mathrm{mg}$ bid. Metformin $1 \mathrm{~g}$ bid was added in 2003 whilst lantus 20 units qhs was started in 2004 due to $\mathrm{HbA}_{1 \mathrm{c}}$ readings around $8 \%$. Repeated ophthalmic exams over the years were normal and he had no history of peripheral vascular disease. He was non-adherent with the use of his CPAP machine. His family history showed that his father suffered from multiple sclerosis and type 2 diabetes, whilst his mother was treated for breast and uterine cancer before dying at the age of 70 from a heart attack. He has 3 siblings with no history for vascular risk factors. He presented to the emergency room with abrupt onset of short term memory loss of twenty-four hour duration. His neurologic exam, physical exam and a CT exam of his head were reported as being normal. Two days later, he presented to his primary care physician with persistant symptoms. He had difficulty finding his way to work, needed reminders by his wife to perform routine daily activities such as eating, taking his medications and he would ask his wife the same question repeatedly. He was unable to remember any recent events or anything up to a week before the onset of symptoms but was able to recall older events. Physical exam in the primary care physician's clinic was normal including his blood pressure. An MRI was performed 10 days after symptom onset.

Diffusion-weighted imaging (DWI) sequence (Figure 1) showed restricted diffusion in the left hippocampal and parahippocampal gyrus and to a lesser

\author{
Corresponding author: \\ David Cachia MD \\ University of Massachusetts \\ 55 Lake Avenue North \\ Worcester \\ MA 01655, USA \\ Phone: +1 7742620577 \\ Fax: +1 7744432756 \\ E-mail: \\ david.cachia@umassmemorial.org
}


extent on the right. ADC mapping (Figure 2) did not show corresponding changes. FLAIR images (Figure 3) showed significant increased signal of the left hippocampal formation and subtle increase on the right. The MRI images were indicative of late subacute infarct affecting the left hippocampal formation, with more chronic changes affecting the right. MRA did not show incranial vascular pathology (Figure 4).

Laboratory investigations included complete blood count, liver function tests, cholesterol, thyroid function tests, arterial blood gas and hypercoaguable workup which were all normal. Patient also had a lumbar puncture and the CSF showed normal results including viral titers and paraneoplastic panel. An electroencephalogram (EEG) done about 2 weeks after symptom onset was normal. A 30 day event monitor did not show any arrythmias. Repeat MRIs showed resolution of DWI changes with no restricted diffusion (Figure 5) but persistence of T2/FLAIR signal abnormalities.

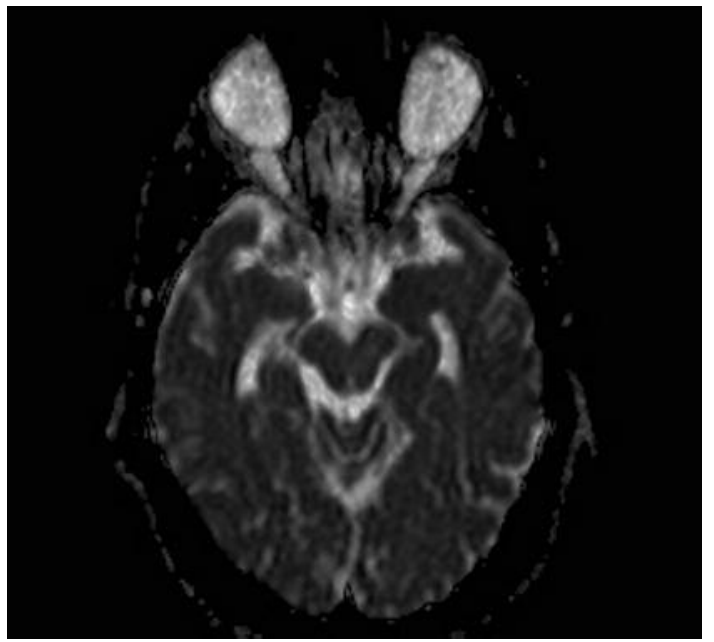

Figure 2. No corresponding abnormality on ADC

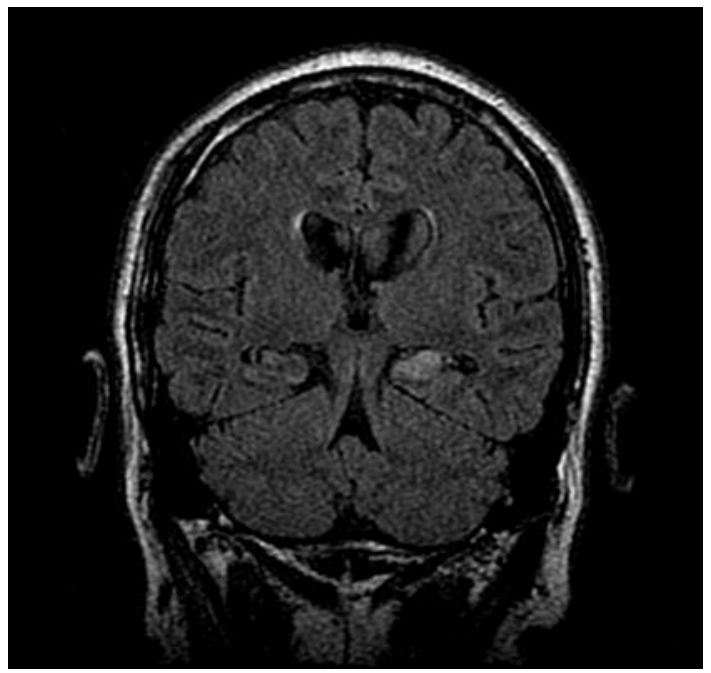

Figure 3. Coronal FLAIR sequence. Increased signal of the hippocampi more prominent on the left

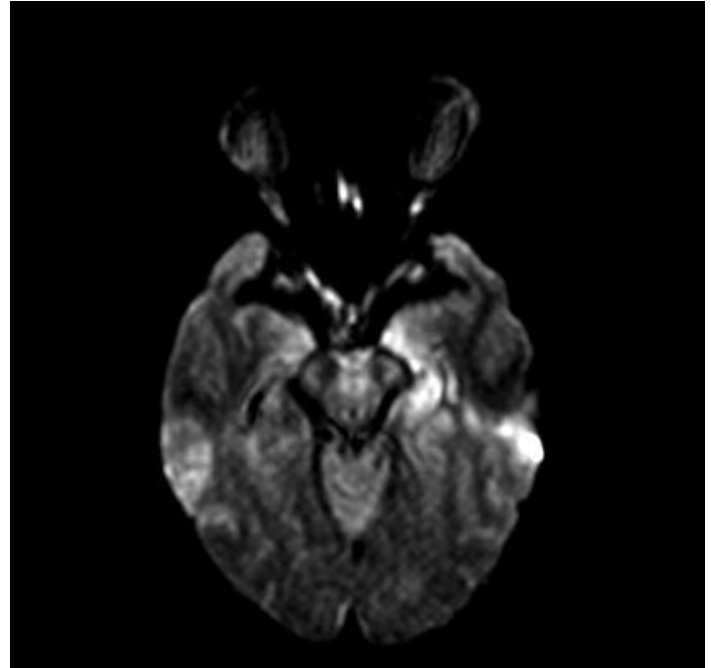

Figure 1. DWI showing restricted diffusion in the hippocampal and parahippocampal gyri more prominent on the left

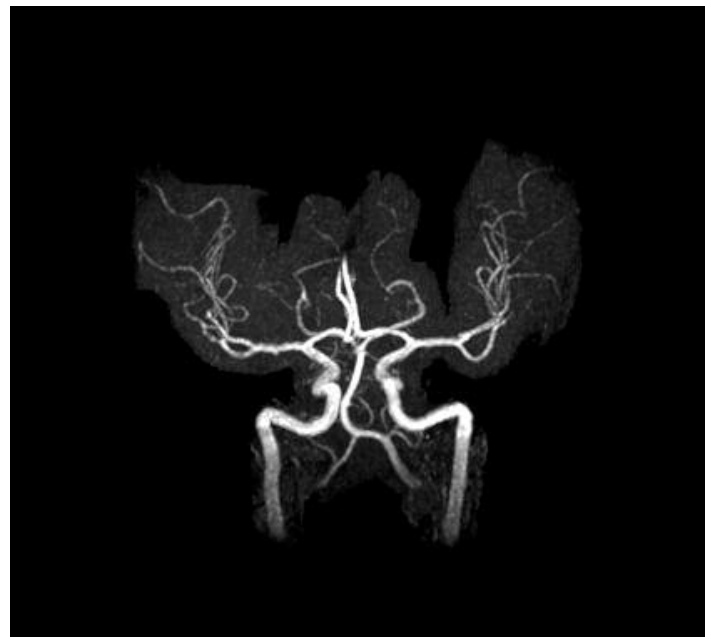

Figure 4. Magnetic resonance angiogram (MRA) showing normal intracerebral vasculature

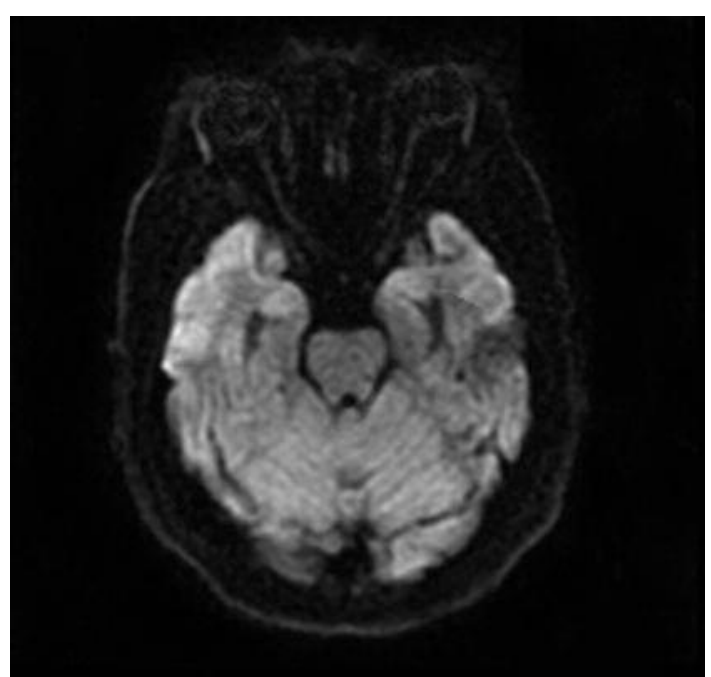

Figure 5. Repeat DWI after 1 month showing no restricted diffusion in the hippocampal and parahippocampal regions 
On neuropsychological evaluation, his general intellectual ability was in the high average range. Vocabulary and fund of knowledge were in the superior range. Expressive and receptive language functions were normal. Visuospatial and visuoconstructive abilities were average/above average. He had difficulties on tests requiring complex concentration and response inhibition but otherwise attention and executive functions were intact on exam. He endorsed a significant degree of emotional and psychological distress on a self-report inventory.

Memory exam showed low average/average immediate memory span. Immediate story recall was also average, but he recalled none of this information after a delay. He had a constricted learning curve on word list (impaired) and he recalled none of the words after a brief or longer delays. A recognition format did not enhance his performance (impaired). Immediate recall of geometric figures was in the average range but he recalled none of this information after a delay.

In summary, our patient's neuropsychological profile was suggestive of a focal and dense antegrade amnestic syndrome.

Preventive risk factor control including adherence to CPAP, glucose and BP control were emphasized while he was continued on his daily $81 \mathrm{mg}$ aspirin.

Table I. Neuropsychological test results*

\begin{tabular}{|c|c|c|c|}
\hline & Initial evaluation & 6 month follow-up & 12 month follow-up \\
\hline Intellectual functions & \multicolumn{3}{|c|}{ Wechsler Adult Intelligence Scale - III [1] } \\
\hline VIQ & $121\left(92^{\text {nd\% }}\right)^{a}$ & -- & $121\left(92^{\text {nd\% }} \%\right)^{a}$ \\
\hline PIQ & $113\left(81^{\text {sto }}\right)^{b}$ & -- & $116\left(86^{\text {tho }} \%\right)^{b}$ \\
\hline FSIQ & $119\left(90^{\text {tho }} \%\right)^{b}$ & -- & $120\left(91^{\mathrm{st}} \%\right)^{\mathrm{b}}$ \\
\hline Memory functions & \multicolumn{3}{|c|}{ Wechsler Memory Scale - III [2] } \\
\hline Digit span forward & $5\left(14^{\text {tho }}\right) d$ & $5\left(14^{\text {tho }}\right)^{d}$ & $\left.5\left(18^{\text {tho }}\right)\right)^{d}$ \\
\hline Digit span backward & $5\left(53^{r d \%} \%\right) c$ & 3 (3rd\%)e & $5\left(58^{\text {tho }}\right) \mathrm{c}$ \\
\hline Logical memory immediate & $43\left(63^{\text {rd\% }}\right)^{c}$ & $42\left(63^{r d \%} \%\right)^{c}$ & $43\left(75^{\text {tho }}\right)^{c}$ \\
\hline Logical memory delayed & $0\left(<1^{\text {sto }}\right)^{f}$ & $0\left(<1^{\text {sto }}\right)^{f}$ & $0\left(<1^{\text {sto }}\right)^{f}$ \\
\hline Verbal paired Associate immediate & -- & $7\left(16^{\text {tho }}\right)$ d & 4 (9th\%)d \\
\hline Verbal paired associate delayed & -- & 0 (2nd\%)e & 0 (5th\%)e \\
\hline Auditory recognition & -- & 49 (37th\%)c & $45\left(16^{\text {th }}\right) \mathrm{d}$ \\
\hline Visual memory immediate & $91\left(75^{\text {tho }}\right) \mathrm{c}$ & $73\left(16^{\text {th }}\right)^{d}$ & $89\left(84^{\text {tho }} \%\right)^{b}$ \\
\hline Visual memory delayed & $0\left(1^{\text {sto }}\right)^{f}$ & $0\left(1^{\text {sto }}\right)^{f}$ & $0\left(1^{\text {sto }}\right)^{f}$ \\
\hline Visual recognition & 3/7 (3rd_9th\%)de & $2 / 7\left(<2^{\text {nd }} \%\right)^{f}$ & $3 / 7$ (10th-16th\%)d \\
\hline Face recognition immediate & -- & $32\left(25^{\text {tho }}\right) \mathrm{c}$ & $37\left(63^{r d \%} \%\right)^{c}$ \\
\hline \multirow[t]{2}{*}{ Face recognition delayed } & -- & $35\left(37^{\text {tho }}\right) \mathrm{c}$ & $35\left(50^{\text {tho }}\right)^{c}$ \\
\hline & \multicolumn{3}{|c|}{ Rey Auditory Verbal Learning Test [3] } \\
\hline List A total & $34\left(4^{\text {tho }} \%\right)^{e}$ & $\left.35\left(6^{\text {th\% }}\right)\right)^{e}$ & $\left.34\left(4^{\text {th\% }}\right)\right)^{e}$ \\
\hline List B & $6\left(53^{\text {rd } \%) c ~}\right.$ & $4\left(19^{\text {tho }}\right) \mathrm{d}$ & -- \\
\hline Immediate & $0\left(<1^{\text {sto }}\right)^{f}$ & $2\left(<1^{\text {sto }} \%\right)^{f}$ & $0\left(<1^{\text {sto }}\right)^{f}$ \\
\hline Delayed & $0\left(<1^{\text {sto }} \%\right)^{f}$ & $0(<1 \text { sto })^{f}$ & $0\left(<1^{\text {sto }}\right)^{f}$ \\
\hline Recognition hits & $4\left(<1^{\text {sto }}\right)^{f}$ & $8\left(<1^{\text {sto }}\right)^{\mathrm{f}}$ & $6\left(<1^{s t} \%\right)^{f}$ \\
\hline \multirow[t]{2}{*}{ False positive errors } & 2 & 6 & 0 \\
\hline & \multicolumn{3}{|c|}{ Rey Complex Figure [4] } \\
\hline Immediate recall & $10\left(2^{\text {nd\% }}\right)$ e & $6.5\left(<1^{\mathrm{st}} \%\right)^{\mathrm{f}}$ & -- \\
\hline Delayed recall & $3\left(<1^{\text {sto }}\right)^{f}$ & $6\left(<1^{\text {sto }} \%\right)^{f}$ & -- \\
\hline
\end{tabular}

*Raw scores for memory tests, age adjusted sum of scaled scores for Verbal IQ (VIQ), Performance IQ (PIQ) and Full Scale IQ (FSIQ), and percentile ranks for age

a Superior performance: $99.99^{\text {th }}$ to $92^{\text {nd }} \%$, b High average performance: $91^{\text {st }}$ to $77^{\text {th }} \%$, cAverage performance: $76^{\text {th }}$ to $25^{\text {th }} \%$, d Low average performance: $24^{\text {th }}$ to $9^{\text {th }} \%$, e Mild/moderately impaired performance: $8^{\text {th }}$ to $2^{\text {nd }} \%$, fSeverely impaired performance: $<2^{\text {nd } \%, ~--~ T e s t ~ n o t ~ d o n e ~ b e c a u s e ~}$ it is not given as part of authors standard neuropsychological test battery (initial evaluation); not necessary (6 month follow-up); or not indicated because performance was poor on less complex tasks (12 month follow-up) 
Cognitive rehabilitation therapy was initiated with some improvement in functioning.

Repeat neuropsychological evaluation was done at 6 and 12 months (Table I). Memory evaluation again showed low average/average intermediate memory span and average immediate story recall but severely impaired delayed recall. Immediate recall of word pairs was low average with some decay over a delay. A recognition format improved performance. Wordlist learning remained severely impaired and a supportive recognition format was not of benefit. Visual memory of geometric figures was in the broad average range on immediate recall, but with significant decay with delay. Recognition was low average to impaired. Recognition was average for unfamiliar faces.

\section{Discussion}

The most likely etiology for our patient's presentation is a combination of factors. We hypothesise that the combination of small vessel disease secondary to diabetes and hypertension, together with hypoxia secondary to untreated sleep apnea might have been the cause of the patient's ischemic events. Since non-valvular atrial fibrillation (AF) causes between $20-25 \%$ of all strokes [5], even though our patient was not known to have AF, the patient had a 30-day event monitor to increase the chance of picking up paroxysmal AF, with negative results.

The fact that the MRI was done 10 days after onset of symptoms would explain why the DWI sequence still showed restricted diffusion but ADC mapping did not show corresponding changes. DWI is sensitive to the self-diffusion of water protons.In ischemia there is water shift between the extracellular and intracellular space. Due to the decreased extracellular water, diffusion is restriced in the extracellular space, resulting in increased signal in DWI whereas the ADC, which is a quantative measure of water diffusion, decreases [6]. ADC normalisation is variable but usually occurs within 10 days of the onset of the ischemic insult [7]. In view of the fact that numerous etiologies can give restricted diffusion on DWI with a normal ADC [8], the patient had an extensive workup for other possible causes. MRA was normal and did not reveal vasospasm making vasospasm-related pathologies, like reversible cerebral vasocontriction syndrome less likely. Small vessel vasculitis usually presents with headaches, multiple lesions and a progressive course which does not fit the presentation of our patient. Though the history of a paraneoplastic syndrome is usually progressive, a paraneoplastic panel including checking for potassium channel antibodies was sent and was negative arguing against a limbic encephalitis. The fact that symptoms persisted, together with the MRI fin- dings, rule out transient global amnesia while the absence of migraine history is against a migraine type pathology. The normal EEG done with the patient still exhibiting anterograde amnesia rules out an epileptiform disorder. Hence the most likely cause in this case remains bilateral sequential small vessel ischemia of the hippocampal regions. As such, no specific interventions such as steroids or intavenous immunoglobulin was tried since no specicific treatment has been shown effective in similar cases.Patient was continued on his antiplatelet medication with stricter control of his diabetes and obstructive sleep apnea.

The bilateral nature of the ischemic events though previously reported is rare [9-11]. The arterial supply of the hippocampus mainly arises from the posterior cerebral artery (PCA) with a minor contribution from the anterior choroidal artery (AchA) [12]. However, many anatomical variations exist. The anterior, middle and posterior hippocampal arteries arise from the P2 segment of the PCA supplying the occipital two-thirds of the hippocampus. The rostral one third is supplied by branches from the AchA. In our patient, the imaging studies suggest a right hippocampal ischemic event occurring first followed by involvement of the left hippocampal formation. A possible explanation for the bilateral nature of the ischemia would be a single artery branching into two to supply both hippocampi much like the artery of Percheron supplies both thalami [13]. Also, a unique feature in this case was that ischemia was limited to the hippocampi and parahippocampal gyri with no other posterior circulation territory was affected.

With regards to the neuropsychological evaluation, the patient showed a dense predominantly antegrade amnesic syndrome which has largely persisted over time. Though there seems to be a consensus that premorbid semantic memory is usually spared with hippocampal lesions, it is not so clear when it comes to what degree episodic memory is affected. In this case, retrograde episodic memory up to a week prior to the onset of symptoms was affected. Why older memories seem to be less affected than recent ones, gave rise to different schools of thought mainly to the standard model of consolidation (SMC) and the multiple trace theory (MTT). According to the SMC, the hippocampus is only involved in consolidating explicit memories [14]. Once consolidated in the neocortex, these memories can be retrieved independently of the hippocampus. The MTT on the other hand states that besides being important in encoding declarative memories, the hippocampal formation is also actively involved in retrieval of these memories [15]. Our patient would tend to favor the SMC theory more than the MTT theory. 
In conclusion, though stroke is unfortunately

a common occurrence in neurological clinical practice, bilateral hippocampal involvement with the resultant debilitating anterograde amnesia is a rare and unique manifestation.

\section{References}

1. Weschler D. Weschler Adult Intelligence Scale. Third edition. The Psychological Corporation, San Antonio 1997.

2. Weschler D. Weschler Memory Scale. Third edition. The Psychological Corporation, San Antonio 1997.

3. Schmidt M. Rey Auditory Verbal Learning Test: a handbook. Western Psychological Services, Los Angeles, CA 1996.

4. Meyers JE, Meyers KR. Rey Complex Figure Test and Recognition Trial: Professional Manual. Psychological Assessment Resources, Lutz, FL 1995.

5 Rizos T, Rasch C, Jenetzky E, et al. Detection of paroxysmal atrial fibrillation in acute stroke patients. Cerebrovasc Dis 2010; 30: 410-7.

6. Hoehn-Berlage M, Norris D, Kohno K, et al. Evolution of regional changes in apparent diffusion coefficient during focal ischemia of rat brain: the relationship of quantitative diffusion NMR imaging to reduction in cerebral blood flow and metabolic disturbances. J Cereb Blood Flow Metab 1995; 15: 1002-11.

7. Fiehler J, Foth $M$, Kucinski T, et al. Severe ADC decreases do not predict irreversible tissue damage in humans. Stroke 2002; 33: 79-86.

8. Moonis M, Fisher M. Imaging of acute stroke. Cerebrovasc Dis 2001; 11: 143-50.

9. Zola-Morgan S, Squire L, Amaral DG. Human Amnesia and Medial Temporal Region: Enduring Memory Impairment following a bilateral lesion limited to field CA1 of the hippocampus. J Neurosci 1986; 6: 2950-67.

10. Kartsounis LD, Rudge P, Stevens JM. Bilateral lesions of CA1 and CA2 fields of the hippocampus are sufficient to cause a severe amnesic syndrome in humans. J Neurol Neurosurg Psychiatry 1995; 59: 95-8.

11. Takahashi S, Higano S, Kurihara N, et al. Correlation of lesions in the hippocampal region noted on MR images with clinical features. Eur Radiol 1997; 7: 281-6.

12. Erdem A, Yargasil G, Roth P. Microsurgical anatomy of the hippocampal arteries. J Neurosurg 1993; 79: 256-65.

13. Percheron $G$. The anatomy of the arterial supply of the human thalamus and its use for the interpretation of the thalamic vascular pathology. Z Neurol 1973; 205: 1-13.

14. Squire LR. Memory and the hippocampus: a synthesis from findings with rats, monkeys and humans. Psychol Rev 1992; 99: 195-231.

15. Moscovitch M, Rosenbaum RS, Gilboa A, et al. Functional neuroanatomy of remote episodic, semantic and spatial memory: a unified account based on multiple trace theory. J Anat 2005; 207: 35-66. 